\title{
Molecular pathology of myelodysplastic syndromes: Biology of medullary stromal and hematopoietic cells (Review)
}

\author{
MASANOBU KITAGAWA, MORITO KURATA, KOUHEI YAMAMOTO, \\ SHINYA ABE, SHIHO SUZUKI and SHIGEAKI UMEDA \\ Department of Comprehensive Pathology, Graduate School, Tokyo Medical and Dental University, Tokyo, Japan
}

Received March 15, 2011; Accepted May 12, 2011

DOI: $10.3892 / \mathrm{mmr} .2011 .493$

\begin{abstract}
Myelodysplastic syndromes (MDS) have been defined as a disease entity based on clinical features and morphological findings. Despite similarities in clinical manifestations, genetic abnormalities occurring in hematopoietic cells are heterogeneous among the syndromes. However, recent investigations have revealed that there are common biological events in the bone marrow of MDS cases. Most notably, excessive apoptosis of hematopoietic cells was observed to be induced by the bone marrow microenvironment. The apoptosis was mediated by paracrine as well as autocrine factors, suggesting that medullary stromal and hematopoietic cells play a role in the pathology of disease. Pro-inflammatory cytokines, such as TNF $\alpha$, in the bone marrow microenvironment are predominantly paracrine mediators of apoptosis. Regarding autocrine stimulation mechanisms, it has recently been shown that the deregulation of ribosomal protein is capable of initiating a stress response in the hematopoietic cell through a p53-mediated signaling pathway. Thus, both the stromal cells of the bone marrow microenvironment and hematopoietic cells themselves possess a common and characteristic biology in this heterogeneous disease entity.
\end{abstract}

\section{Contents}

1. Introduction

2. Excessive apoptosis in the MDS bone marrow: cytokines and the bone marrow microenvironment

3. Recent findings for hematopoietic cell defects of MDS

4. Animal models of MDS

5. Conclusions

Correspondence to: Dr Masanobu Kitagawa, Department of Comprehensive Pathology, Graduate School, Tokyo Medical and Dental University, 1-5-45 Yushima, Bunkyo-ku, Tokyo 113-8519, Japan

E-mail: masa.pth2@tmd.ac.jp

Key words: myelodysplastic syndromes, stromal cell, hematopoietic cell, apoptosis

\section{Introduction}

Myelodysplastic syndromes (MDS) are characterized by the clinical manifestation of a variable cytopenia, despite normo- or hypercellular bone marrow, with a subset of cases progressing to overt leukemia (OL). MDS occur predominantly in the elderly and thus, the prevalence of patients with MDS is on the increase due to an aging population and increased awareness of these syndromes. In MDS bone marrow, it has been postulated that hematopoietic stem cells are initially exposed to genetic hits that eventually cause abnormality, and then develop a growth advantage over their normal counterparts, leading to clonal expansion and monoclonal hematopoiesis (1,2) (Fig. 1). Cell cycle kinetic studies demonstrated that MDS bone marrow is actively proliferative and cycling more rapidly than even normal bone marrow cells (3). However, despite such active proliferation of bone marrow cells, the presence of cytopenias (ineffective hematopoiesis) remains to be elucidated (Fig. 1). This review summarizes the mechanism of the underlying ineffective hematopoiesis in MDS, which appears to be caused by the apoptotic death of hematopoietic cells. In early MDS, stromal and hematopoietic cells produce high levels of pro-apoptotic cytokines, whereas in advanced MDS or OL, these cells produce anti-apoptotic molecules (Fig. 1). Therefore, apoptosis was the key finding inducing common and significant biologic characteristics in different sub-types of MDS patients. Regarding MDS bone marrow, a number of additional common abnormalities have recently been reported and are evaluated in this review.

2. Excessive apoptosis in the MDS bone marrow: cytokines and the bone marrow microenvironment

Cytokines and their receptors. The paradox of cytopenia, despite cellular marrow in MDS patients, was resolved by findings regarding programmed cell death in the 1990s. The excessive proliferation of bone marrow cells in MDS patients appeared to correspond to an equally excessive intramedullary apoptosis of hematopoietic cells (4-7). This apoptosis was observed in all FAB categories of MDS patients, although the frequency was higher in the early stage of disease and proportionately lower in patients with an increasing percentage of blasts. Furthermore, it was shown that excessive apoptosis was mediated by a number of pro-apoptotic factors, including pro- 
inflammatory cytokines that were overexpressed in the MDS bone marrow. These factors include tumor necrosis factor $\alpha$ (TNF $\alpha$ ), interferon $\gamma$ (IFN $\gamma$ ), transforming growth factor $\beta$ (TGF $\beta$ ), interleukin $1 \beta$, FAS-ligand (FAS-L) and inducible nitric oxide synthase (5-11). Pro-apoptotic factors, such as FAS-L were mainly produced by stromal cells, including macrophages, or partly by hematopoietic cells, whereas receptors, such as FAS and TNF receptor (TNFR), were expressed in hematopoietic cells $(6,12)$.

As indicated by Raza et al (13), a second crucial paradox at this point was the presence of clonal expansion and monoclonality in cells that showed a tendency for apoptotic death. A model was proposed to explain this second paradox in which an unknown, poorly understood, initial lesion in a pluripotential hematopoietic stem cell leads to this cell developing a growth advantage (8). The cells are stimulated further to proliferate through the effects of pro-inflammatory cytokine TNF $\alpha$. This proliferation eventually leads to a monoclonal hematopoiesis. Notably, as the daughter cells mature, TNF $\alpha$ driving the proliferation of the progenitors is capable of exerting a dual action, in that apoptosis is induced in the maturing progeny. This phenomenon was supported by demonstrating a shift in the expression of the cytokine receptors of hematopoietic cells in MDS. Pro-apoptotic receptor TNFRI and pro/anti-apoptotic receptor TNFRII were expressed differentially in response to the disease stages (12). The tendency to undergo apoptosis is not inherited uniformly by all the cells of the subsequent generations; instead, there is a spectrum of sensitivity to pro-inflammatory cytokines. The cells most sensitive to apoptosis are those undergoing apoptotic death in the bone marrow, whereas apoptosis-resistant cells actually enter the bloodstream. This phenomenon has been supported by the finding that granulocytes in MDS patients, although clonal in nature, are more resistant to apoptosis than granulocytes obtained from normal, healthy donors (14).

Early hematopoietic progenitor appears to develop a growth advantage and clonal expansion, leading to monoclonality. The subsequent generations of this transformed clone have an unequal tendency towards apoptotic death in the presence of increased amounts of a cascade of pro-inflammatory cytokines. One of the key systems for this switching appears to be TNF $\alpha$ and its receptors. Therefore, MDS should be considered as a disease of not only hematopoietic cells, but also of the bone marrow microenvironment, a concept that becomes critical when developing therapeutic strategies. Thus, cell proliferation followed by marked apoptosis was the most significant biological characteristic present in all subtypes of MDS.

Angiogenic factors. The bone marrow microenvironment of MDS is also affected by the production of angiogenetic factors and matrix metalloproteinases (MMPs), which may regulate marrow microvascular density (MVD). Bellamy et al (15) have reported that in hematopoietic cells of MDS, the production of vascular endothelial growth factor (VEGF) and its receptor may promote leukemia progenitor self-renewal and cytokine elaboration and may also provide a biological condition for the generation of foci of abnormal localized immature precursors in advanced disease. Verstovsek et al
(16) reported that VEGF expression is the determining factor of the biological behavior of MDS and AML. Findings of a recent study revealed a significant increase in marrow MVD in de novo AML patients compared to controls (17). In MDS marrow, MVD was higher than that of controls, but lower than that of de novo AML patients. MDS patients exhibited a significantly lower MVD following transformation to OL, as demonstrated by a pairwise comparison of samples collected from the same patient on diagnosis and at leukemic evolution. Furthermore, AML secondary to MDS revealed a MVD lower than that of de novo AML patients, similar to that of healthy controls. Genes encoding for pro-angiogenic factors exhibited a similar expression pattern. Of note, TGF $\beta$, an anti-angiogenic mediator, exhibited an opposite expression pattern, since its expression was higher in AML secondary to MDS than in MDS and de novo AML.

Matrix metalloproteinases. Concerning the role of MMP in MDS bone marrow, Iwata et al (18) demonstrated that stromal cells induced the expression of MMP-9 in monocytes. MMP-9 expression was inversely correlated with bone marrow cellularity and percentage of cytogenetically abnormal cells. In their study, Travaglino et al (19) showed that MMP-2 and MMP-9 expression levels were higher in MDS patients than in healthy controls. The two MMPs localized in the cytoplasm of maturing myeloid cells. A positive correlation was observed between MMP-2 erythroblast expression and erythroid dysplasia, and an inverse correlation was observed between MMP-2/MMP-9 myeloid expression and marrow blast cell percentages. Particularly, in early MDS, the abnormal MMP expression profile correlated with an increased apoptotic rate, and high MMP levels were associated with longer overall and evolution-free survival.

Niche-induced myelodysplasia: bone progenitor dysfunction. The majority of normal and malignant tissues appear to form 'stroma' with specific mesenchymal cell involvement in the regulatory niches of stem cells. By examining the manner in which mesenchymal osteolineage cells of the bone marrow modulate hematopoiesis, Raaijmakers et al (20) showed that deletion of Dicerl disrupts the integrity of hematopoiesis in mouse osteoprogenitors, but not in mature osteoblasts. These mice exhibited myelodysplasia followed by the development of AML that had acquired several genetic abnormalities, whereas Dicerl remained intact. As a result of Dicerl deletion, the expression of Sbds was reduced. Sbds is the gene mutated in Schwachman-Bodian-Diamond syndrome, a human bone marrow failure and leukemia pre-disposition condition. As expected, deletion of $S b d s$ in mouse osteoprogenitors induced bone marrow dysfunction with myelodysplasia. Therefore, perturbation of specific mesenchymal subsets of stromal cells disorders differentiation, proliferation and apoptosis of heterologous cells, and disrupts tissue homeostasis. This study clearly indicated the essential role of niche as well as the microenvironment in the pathogenesis of MDS.

\section{Recent findings for hematopoietic cell defects of MDS}

The majority of MDS and AML patients harbor cytogenetic and molecular defects that identify entities with specific 


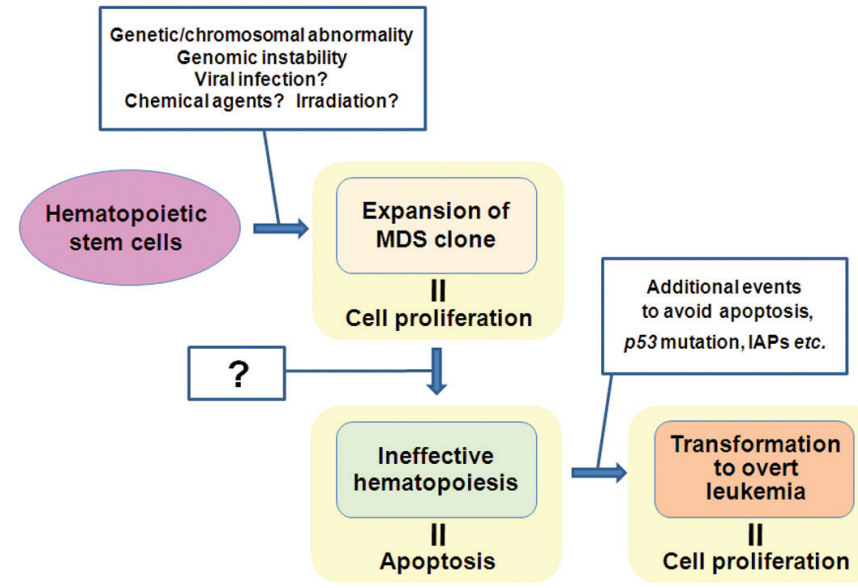

Figure 1. Schematic illustration of the development of myelodysplastic syndromes (MDS) and overt leukemia (OL) with characteristic biological events. The initial expansion of the MDS clone should be associated with cell proliferation, whereas ineffective hematopoiesis occurs with apoptosis. The evolution of OL is accompanied by cell proliferation by avoiding the apoptotic pathways.

biological/clinical features and distinct therapeutic responses (21-26). The incidence of chromosomal abnormalities is 40-60\% in de novo MDS, 50-60\% in AML and 70-90\% in secondary MDS/AML (sMDS/sAML). A significant point that indicates a distinct pathogenesis for MDS and AML is that the genetic defects observed in de novo MDS are different from those of de novo AML. In de novo MDS, the incidences of chromosomal lesions with deletions (50\%) and numerical defects $(10 \%)$ dominate over the incidence of chromosomal translocations $(<5 \%)$, although the most common cytogenetic abnormalities of AML are the balanced translocations (40\%) (22). Thus, the hematopoietic cell (or myeloid blast) defects of MDS appear to be distinct from those of de novo AML.

Genetic bases of $5 q^{-}$syndrome. A special type of MDS involving an isolated del(5q) is called $5 q^{-}$syndrome (27). The syndrome is characterized by macrocytic anemia, normal or slightly elevated platelet counts, normal blast count, hypolobated megakaryocytes and a long-term risk of OL evolution of approximately $10 \%$ (28).

Bone marrow in $5 \mathrm{q}^{-}$syndrome is essentially normo- or hypercellular with $>90 \%$ of the hematopoietic stem cells being clonal (29). Despite the expansion of immature hematopoietic cells, the clinical manifestation is anemia, designated as ineffective hematopoiesis. By knocking down all 40 genes located within the common deleted region (CDR) at 5q32-33, Ebert et al (30) demonstrated that a decreased expression of RPS14 results in poor erythroid development and increased erythroid apoptosis. Forced expression of RPS14 in del(5q) marrow progenitors rescued the disease phenotypes. RPS14 is a ribosomal gene, coding for a component of the ribosomal subunit 40S. Other ribosomal genes, in particular RPS19, have been shown to cause Diamond-Blackfan anemia (31), also characterized by a macrocytic anemia. In addition, animal models have demonstrated that defects in ribosomal genes may increase the risk of cancer (32).

Using large parallel sequencing of small RNA libraries, Starczynowski and Karsan (33) identified two down-regulated

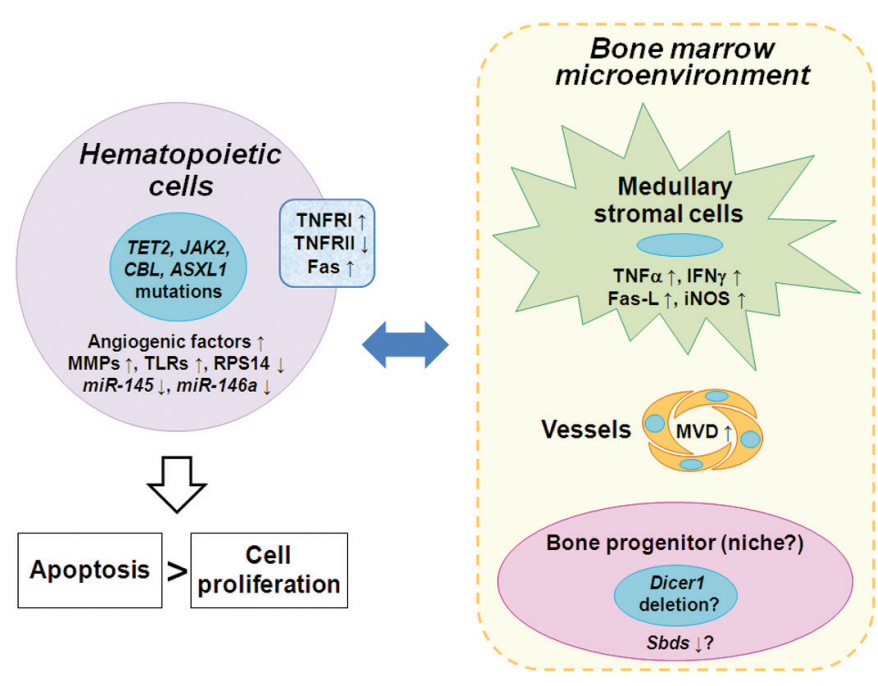

Figure 2. Abnormalities in hematopoietic cells and bone marrow microenvironment such as stromal cells, vessels and bone progenitors identified in MDS. Genetic mutations described in the nucleus of the hematopoietic cells do not include conventional mutations/abnormalities such as abnormalities of NRAS, FLT3, MLL, NF1, CSF1R, KIT, CDKN2B, TP53, RB1, EVI1, IRF1, $A M L 1, W T 1$ and NPM1.

micro-RNAs, $m i R-145$ and $m i R-146 a$, located close to the $\mathrm{CDR}$ on $5 \mathrm{q}$ and with an abundant expression in marrow progenitors. Knock-down of $m i R-145$ and $m i R-146 a$ leads to a phenotype with key features of the $5 \mathrm{q}^{-}$syndrome; i.e., hypolobated megakaryocytes and peripheral thrombocytosis. Moreover, predicted targets for $m i R-145$ and $m i R-146 a$ were associated with the innate immune response pathway. Two genes in the Toll-like receptor signaling pathway were verified as true targets: TIRAP for $m i R-145$ and TRAF6 for miR-146a. TIRAP interacts with TRAF6 and subsequently results in the activation of NF- $\mathrm{KB}$. A proportion of mice transplanted with TRAF6 overexpressing marrow developed bone marrow failure or AML in due course.

A mouse model of $5 \mathrm{q}^{-}$syndrome has been generated (34). Since the CDR of $5 \mathrm{q}^{-}$syndromes is split into two regions in mice, on chromosomes 11 and 18, chromosomal engineering was used to delete small segments within these regions. The only deletion that exhibited a clear phenotype was the Rps14 gene, leading to macrocytic anemia. Rpsl4-deficient mice were then bred with $p 53$ knockout mice resulting in a reversal of the phenotype. This reversal indicates that $p 53$-mediated cell death or growth inhibition may be crucial for RPS14induced anemia in $5 \mathrm{q}^{-}$syndrome.

As summarized by Jädersten and Eva Hellström-Lindberg (35), various genetic alterations cooperate to induce the characteristic phenotype of $5 \mathrm{q}^{-}$syndrome. The anemia is likely to be caused by RPS14 deficiency, while hypolobated megakaryocytes and thrombocytosis may be the result of a deficiency of $m i R-145$ and $m i R-146 a$. However, the CDR of 5q- syndromes contains a number of other genes that may be of importance for clonal expansion, such as the tumor suppressor gene, SPARC (36). SPARC is anti-adhesive and modulates the cell matrix, induces apoptosis and may inhibit angiogenesis (37). Haploinsufficiency of SPARC may increase the adhesion of the hematopoietic stem cells to the supporting stromal cells and provide a clonal advantage for proliferation. 
Novel gene mutations identified in MDS. Although the frequency is not usually high, various novel mutations have been identified in patients with MDS. JAK2 mutations (the most common one being V617F) were found in a significant proportion of patients with myeloproliferative neoplasms (MPN) (38), leading to the constitutive activation of proliferative and survival signaling in hematopoietic cells. In addition, an activating mutation in the thrombopoietin receptor (MPL) has been found in a small proportion of essential thrombocythemia and primary myelofibrosis (39). Multipotent hematopoietic stem cells with these mutations generate a myeloid clone that expands to replace hematopoietic cells without the mutation (40). These types of gene mutations have also been reported in MDS and MDS/MPN. JAK2 mutations occur in approximately $50 \%$ of patients with RARS with marked thrombocytosis (RARS-T), although the mutation is extremely rare in RARS with normal platelet count $(41,42)$.

In 2009, mutations in the Ten-Eleven Translocation-2 (TET2) gene located on $4 \mathrm{q}$ were found in MDS and MPN (43-47). Among 320 patients with myeloid malignancies, TET2 mutations were found in $12 \%$ of patients with MPN, $19 \%$ of MDS and $22 \%$ of patients with CMML (44). Moreover, hematopoietic stem cells (HSC) harboring the mutation had a growth advantage compared to normal HSC. Another study revealed that $26 \%$ of 102 MDS patients carried TET2 mutations (46). These TET2 mutations were found to be more frequent in IPSS low (41\%) and intermediate-1 risk (27\%) MDS patients than in those with intermediate-2 (13\%) and high-risk (14\%) MDS. However, the prognostic significance of TET2 remains controversial (48). Although the cellular function of TET2 is unknown, TET1 was revealed to mediate the conversion of 5-methylcytosine to 5-hydroxymethylcytosine, and was involved in the epigenetic control of the gene expression (49). Therefore, TET2 appears to be involved in DNA methylation.

Recently, mutation of the $C$-cbl E3 ubiquitin ligase gene $(C B L)$ that is located on chromosome 11q was found in MDS and MDS/MPN. This ligase is involved in the degradation of receptor tyrosine kinases, and its inactive mutation may cause a growth advantage in the hematopoietic cells. The $C B L$ mutation was identified in 2 of $38(5 \%)$ patients with CMML and 10 of 110 (9\%) with secondary AML (50). However, only 1 of $115(1 \%)$ of the patients with MDS carried mutant $C B L$. Mutations were revealed to associate with poor survival on multivariate analysis.

Another recently identified gene mutation in MDS is the polycomb-associated gene ASXL1, which is involved in the regulation of chromatin remodeling. ASXL1 mutations were found in $11 \%$ of $35 \mathrm{MDS}$ patients and $43 \%$ of the $39 \mathrm{CMML}$ cases (51). Boultwood et al studied 300 patients with MDS and AML and found that 62 (21\%) patients carried an ASXL1 mutation (52). The mutation was observed in 5 of $79(6 \%)$ RA patients, 17 of 55 (31\%) RAEB-1 or RAEB-2 patients and 17 of 67 (25\%) AML patients. Thus, the mutation was more frequent in high-risk MDS and AML patients compared to lower-risk MDS patients.

Uniparental disomy. Small genetic lesions, such as uniparental disomy (UPD), have been identified by high-density single nucleotide polymorphism (SNP) arrays. In MDS patients,
$10-15 \%$ of those with normal karyotypes had regions of DNA that were derived from only one parent. This phenomenon has been termed UPD (53-55). In addition, small genetic lesions such as amplifications and deletions, which had remained undetected on conventional cytogenetics or FISH analyses, were also identified. UPDs were constitutional and not limited to the clonal cells, whereas the amplifications and deletions proved to be acquired. These data suggest that individuals who are born with constitutional UPDs are predisposed toward genetic instability and are at an increased risk of developing MDS. For example, the TET2 gene mutation is known to be frequently affected by UPD (47).

Toll-like receptor. Toll-like receptors (TLRs) play a crucial role in host defense against invading microorganisms by identifying pathogen-associated molecular patterns $(56,57)$. A number of endogenous molecules have been reported to be ligands of TLRs (58). Some of these molecules are known to be expressed in cancer tissue and to activate intracellular signal pathways via TLRs during cancer progression. At the time of initial diagnosis, MDS bone marrow hematopoietic cells tended to express higher levels of TLR2, TLR4 and TLR9 than control bone marrow cells (59). Among these TLRs, TLR9 exhibited a significant decrease of expression at the time of transformation to OL. The expression of TLR9 and $\mathrm{TNF} \alpha$ showed a significant correlation in bone marrow cells from patients with MDS and OL. Bone marrow cells in MDS exhibit frequent apoptosis, whereas OL cells are prone to immortality. Thus, TLR9 may be associated with the regulation of apoptotic/proliferative signals via TNF $\alpha$ in the MDS bone marrow.

\section{Animal models of MDS}

Although MDS is characterized by numerous complex phenotypes, such as ineffective hematopoiesis, peripheral blood cytopenias, morphological dysplasia of hematopoietic cells and susceptibility to OL evolution, attempts have been made to generate effective animal models mimicking MDS pathology. These models include Evi-l overexpression in a mouse bone marrow transplantation (BMT) system, Npml hetero mice, Nup98/HoxD3 transgenic mice, mutated Amllbearing BMT system and Dicerl deletion mouse system. In mouse hematopoietic organs, a forced expression of Evi-1 initially determines an excessive proliferation of bone marrow cells with the down-regulation of genes involved in erythroid differentiation and platelet formation followed by a profound and fatal peripheral cytopenia resembling human MDS (60). However, the condition does not progress to leukemia unexpectedly. $\mathrm{Npm}^{+/-}$mice exhibited features resembling MDS, although $\mathrm{Npm}^{-/}$mice showed embryonic lethality (61). In contrast to the Evi-1 model, these mice developed hematological malignancies of myeloid as well as lymphoid origin after a 2-year follow-up.

Similarly, Nup98/HoxD13 transgenic mice develop a disease that faithfully exemplifies all the key features of MDS, including peripheral blood cytopenias, bone marrow dysplasia, apoptosis and transformation to OL (62). These mice exhibit a uniformly fatal MDS, dying of either severe anemia/leucopenia or leukemic evolution. However, mice with 
BMT of Nup98/HoxD13 cells did not develop OL. A recent study demonstrated that the BMT of Amll mutants exhibited MDS-like features and evolution to OL (63). In this model, different mutations of Amll resulted in different types of MDS. Finally, results from the Dicerl deletion mouse system were highly significant (20). As described above in the section on microenvironment-niche-induced myelodysplasia, these results clearly revealed the significance of niche-like bone progenitor cells in the pathogenesis of MDS.

\section{Conclusions}

As shown in Fig. 1, a heterogeneous disease entity, MDS, is a complex regulation of cell dynamics, resulting in cellular proliferation and/or apoptosis. Under the various phenotypic manifestations, common biology may exist as regulatory mechanisms. One of the most characteristic of these mechanisms, distinct from AML and MPN, is the induction of apoptosis in hematopoietic cells. Fig. 2 summarizes the genetic/molecular modifications recently identified in the bone marrow of MDS. Interaction between hematopoietic cells and the bone marrow microenvironment is likely to define the balance between apoptosis/cell proliferation of MDS bone marrow cells.

Apoptosis is induced in hematopoietic cells only when the subsequent generations of the initial MDS progenitor cell mature and begin to express the appropriate cytokine receptors. These insights led to the novel translational approach of using anti-cytokine therapy to improve the cytopenias by protecting the maturing cells from dying. This strategy was attempted without a serious concern for causing leukemic transformation as the therapeutic procedure did not affect earlier progenitors. Since the rate of apoptosis is inversely related to the risk of transformation, this strategy was ideal for patients with lower-risk MDS where anti-TNF agents such as thalidomide, lenalidomide, infliximab and etanercept have been found to be effective in improving cytopenias in a subset of patients. Notably, even high-risk patients have the same incidence of apoptosis in the maturing cells as lowerrisk patients. The fact that the immature blasts are not dying, accounts for the lower overall incidence of apoptosis in this group.

\section{References}

1. Raza A, Preisler HD, Mayers GL and Bankert R: Rapid enumeration of S-phase cells by means of monoclonal antibodies. N Engl J Med 310: 991, 1984.

2. Raza A, Maheshwari Y and Preisler HD: Differences in cell cycle characteristics among patients with acute nonlymphocytic leukemia. Blood 69: 1647-1653, 1987.

3. Kitagawa M, Kamiyama R and Kasuga T: Expression of the proliferating cell nuclear antigen in bone marrow cells from patients with myelodysplastic syndromes and aplastic anemia. Hum Pathol 24: 359-363, 1992.

4. Raza A, Gezer S, Mundle S, et al: Apoptosis in bone marrow biopsy samples involving stromal and hematopoietic cells in 50 patients with myelodysplastic syndromes. Blood 86: 268-276, 1995.

5. Kitagawa M, Saito I, Kuwata T, Yoshida S, Yamaguchi S, Takahashi M, Tanizawa T, Kamiyama R and Hirokawa K: Overexpression of tumor necrosis factor (TNF)- $\alpha$ and interferon (IFN)- $\gamma$ by bone marrow cells from patients with myelodysplastic syndromes. Leukemia 11: 2049-2054, 1997.
6. Kitagawa M, Yamaguchi S, Takahashi M, Tanizawa T, Hirokawa $\mathrm{K}$ and Kamiyama R: Localization of Fas and Fas ligand in bone marrow cells demonstrating myelodysplasia. Leukemia 12: 486-492, 1998

7. Kitagawa M, Takahashi M, Yamaguchi S, Inoue M, Ogawa S, Hirokawa $\mathrm{K}$ and Kamiyama R: Expression of inducible nitric oxide synthase (NOS) in bone marrow cells of myelodysplastic syndromes. Leukemia 13: 699-703, 1999.

8. Raza A, Gregory SA and Preisler HD: The myelodysplastic syndromes in 1996: complex stem cell disorders confounded by dual actions of cytokines. Leuk Res 20: 881-890, 1996.

9. Mundle SD, Ali A, Cartlidge JD, Reza S, Alvi S, Showel MM, Mativi BY, Shetty VT, Venugopal P, Gregory SA and Raza A: Evidence for involvement of tumor necrosis factor- $\alpha$ in apoptotic death of bone marrow cells in myelodysplastic syndromes. Am J Hematol 60: 36-47, 1999.

10. Claessens YE, Bouscary D, Dupont JM, Picard F, Melle J, Gisselbrecht S, Lacombe C, Dreyfus F, Mayeux P and Fontenay-Roupie M: In vitro proliferation and differentiation of erythroid progenitors from patients with myelodysplastic syndromes: evidence for Fas-dependent apoptosis. Blood 99: 1594-1601, 2002.

11. Campioni D, Secchiero P, Corallini F, Melloni E, Capitani S, Lanza $\mathrm{F}$ and Zauli G: Evidence for a role of TNF-related apoptosis-inducing ligand (TRAIL) in the anemia of myelodysplastic syndromes. Am J Pathol 166: 557-563, 2005.

12. Sawanobori M, Yamaguchi S, Hasegawa M, Inoue M, Suzuki K, Kamiyama R, Hirokawa K and Kitagawa M: Expression of TNF receptors and related signaling molecules in the bone marrow from patients with myelodysplastic syndromes. Leukemia Res 27: 583-591, 2003.

13. Raza A, Cruz R, Latif T, Mukherjee S and Galili N: The biology of myelodysplastic syndromes: unity despite heterogeneity. Hemato Rep 2: 28-31, 2010.

14. Horikawa $K$, Nakakuma $H$, Kawaguchi $T$, Iwamoto $N$, Nagakura S, Kagimoto T and Takatsuki K: Apoptosis resistance of blood cells from patients with paroxysmal nocturnal hemoglobinuria, aplastic anemia, and myelodysplastic syndrome. Blood 90: 2716-2722, 1997.

15. Bellamy WT, Richter L, Sirjani D, Roxas C, Glinsmann Gibson B, Frutiger Y, Grogan TM and List AF: Vascular endothelial cell growth factor is an autocrine promoter of abnormal localized immature myeloid precursors and leukaemia progenitor formation in myelodysplastic syndromes. Blood 97: 1427-1434, 2001.

16. Verstovsek S, Estey E, Manshouri T, Giles FJ, Cortes J, Beran M, Rogers A, Keating M, Kantarjian H and Albitar M: Clinical relevance of vascular endothelial growth factor receptors 1 and 2 in acute myeloid leukaemia and myelodysplastic syndromes. Br J Haematol 118: 151-156, 2002

17. Keith T, Araki Y, Ohyagi M, Hasegawa M, Yamamoto K, Kurata M, Nakagawa Y, Suzuki K and Kitagawa M: Regulation of angiogenesis in the bone marrow of myelodysplastic syndromes transforming to overt leukaemia. Br J Haematol 137: 206-215, 2007.

18. Iwata M, Pillai M, Ramakrishnan A, Hackman RC, Deeg HJ, Opdenakker G and Torok-Storb B: Reduced expression of inducible gelatinase $\mathrm{B} /$ matrix metalloproteinase-9 in monocytes from patients with myelodysplastic syndrome: correlation of inducible levels with the percentage of cytogenetically marked cells and with marrow cellularity. Blood 109: 85-92, 2007.

19. Travaglino E, Benatti C, Malcovati L, Della Porta MG, Galli A, Sonetti E, Rosti V, Cazzola M and Invernizzi R: Biological and clinical relevance of matrix metalloproteinases 2 and 9 in acute myeloid leukemias and myelodysplastic syndromes. Eur J Haematol 80: 216-226, 2008.

20. Raaijmakers MH, Mukherjee S, Guo S, et al: Bone progenitor dysfunction induces myelodysplasia and secondary leukaemia. Nature 464: 852-857, 2010.

21. Greenberg P, Cox C, LeBeau MM, et al: International Scoring System for evaluating prognosis in myelodysplastic syndromes. Blood 89: 2079-2088, 1997.

22. Olney JH and Le Beau MM: The cytogenetics of myelodysplastic syndromes. Best practice and research. Clin Haematol 14: 479-495, 2001.

23. Byrd JC, Mrózek K, Dodge RK, et al: Pretreatment cytogenetic abnormalities are predictive of induction success, cumulative incidence of relapse, and overall survival in adult patients with de novo acute myeloid leukaemia: results from Cancer and Leukemia Study Group B (CALGB 8461). Blood 100: 4325-4336, 2002. 
24. Bernasconi P, Klersy C, Boni M, Cavigliano PM, Calatroni S, Giardini I, Rocca B, Zappatore R, Caresana M, Lazzarino M and Bernasconi $\mathrm{C}$ : Incidence and prognostic significance of karyotype abnormalities in de novo primary myelodysplastic syndromes: a study on 331 patients from a single institution. Leukemia 19: 1424-1431, 2005.

25. Bernasconi P, Klersy C, Boni M, Cavigliano PM, Calatroni S, Giardini I, Rocca B, Zappatore R, Caresana M, Dambruoso I, Lazzarino $\mathrm{M}$ and Bernasconi C: World Health Organization classification in combination with cytogenetic markers improves the prognostic stratification of patients with de novo primary myelodysplastic syndromes. Br J Haematol 137: 193-205, 2006.

26. Haase D, Germing U, Schanz J, et al: New insights into the prognostic impact of karyotype in MDS and correlations with subtypes: evidence from a core dataset of 2124 patients. Blood 110: 4385-4395, 2007.

27. Van den Berghe H, Cassiman JJ, David G, Fryns JP, Michaux JL and Sokal G: Distinct haematological disorder with deletion of long arm of no. 5 chromosome. Nature 251: 437-438, 1974.

28. Giagounidis AA, Germing U, Haase S, Hildebrandt B Schlegelberger B, Schoch C, Wilkens L, Heinsch M, Willems H, Aivado M and Aul C: Clinical, morphological, cytogenetic, and prognostic features of patients with myelodysplastic syndromes and del(5q) including band q31. Leukemia 18: 113-119, 2004.

29. Nilsson L, Astrand-Grundstrom I, Arvidsson I, Jacobsson B, Hellstrom-Lindberg E, Hast R and Jacobsen SE: Isolation and characterization of hematopoietic progenitor/stem cells in 5q-deleted myelodysplastic syndromes: evidence for involvement at the hematopoietic stem cell level. Blood 96: 2012-2021, 2000.

30. Ebert BL, Pretz J, Bosco J, Chang CY, Tamayo P, Galili N, Raza A, Root DE, Attar E, Ellis SR and Golub TR: Identification of RPS14 as a 5q- syndrome gene by RNA interference screen. Nature 451: 335-339, 2008

31. Draptchinskaia N, Gustavsson $\mathrm{P}$, Andersson B, et al: The gene encoding ribosomal protein S19 is mutated in DiamondBlackfan anaemia. Nature Gen 21: 169-175, 1999.

32. Amsterdam A, Sadler KC, Lai K, Farrington S, Bronson R, Lees JA and Hopkins N: Many ribosomal protein genes are cancer genes in zebrafish. PLoS Biol 2: E139, 2004.

33. Starczynowski DT, Kuchenbauer F, Argiropoulos B, et al: Identification of miR-145 and miR-146a as mediators of the 5qsyndrome phenotype. Nature Med 16: 49-58, 2010.

34. Barlow JL, Drynan LF, Hewett DR, et al: A p53-dependent mechanism underlies macrocytic anemia in a mouse model of human 5q- syndrome. Nature Med 16: 59-66, 2010.

35. Jädersten $M$ and Hellström-Lindberg E: New clues to the molecular pathogenesis of myelodysplastic syndromes. Exp Cell Res 316: 1390-1396, 2010.

36. Pellagatti A, Jadersten M, Forsblom AM, et al: Lenalidomide inhibits the malignant clone and up-regulates the SPARC gene mapping to the commonly deleted region in 5q- syndromepatients. Proc Natl Acad Sci USA 104: 11406-11411, 2007.

37. Framson PE and Sage EH: SPARC and tumor growth: where the seed meets the soil? J Cell Biochem 92: 679-690, 2004.

38. James C, Ugo V, Le Couedic JP, et al: A unique clonal JAK2 mutation leading to constitutive signaling causes polycythaemia vera. Nature 434: 1144-1148, 2005.

39. Pikman Y, Lee BH, Mercher T, et al: MPLW515L is a nove somatic activating mutation in myelofibrosis with myeloid metaplasia. PLoS Med 3: e270, 2006.

40. Scott LM, Tong W, Levine RL, et al: JAK2 exon 12 mutations in polycythemia vera and idiopathic erythrocytosis. N Engl J Med 356: 459-468, 2007

41. Szpurka H, Tiu R, Murugesan G, Aboudola S, His ED, Theil KS Sekeres MA and Maciejewski JP: Refractory anemia with ringed sideroblasts associated with marked thrombocytosis (RARS-T), another myeloproliferative condition characterized by JAK2 V617F mutation. Blood 108: 2173-2181, 2006

42. Ingram W, Lea NC, Cervera J, et al: The JAK2 V617F mutation identifies a subgroup of MDS patients with isolated deletion 5c and a proliferative bone marrow. Leukemia 20: 1319-1321, 2006.

43. Abdel-Wahab O, Mullally A, Hedvat C, et al: Genetic characterization of TET1, TET2, and TET3 alterations in myeloid malignancies. Blood 114: 144-147, 2009.
44. Delhommeau F, Dupont, S, della Valle V, et al: Mutation in TET2 in myeloid cancers. N Engl J Med 360: 2289-2301, 2009.

45. Jankowska AM, Szpurka H, Tiu RV, Makishima H, Afable M, Huh J, O'Keefe CL, Ganetzky R, McDevitt MA and Maciejewski JP: Loss of heterozygosity 4q24 and TET2 mutations associated with myelodysplastic/myeloproliferative neoplasms. Blood 113: 6403-6410, 2009.

46. Langemeijer SM, Kuiper RP, Berends M, et al: Acquired mutations in TET2 are common in myelodysplastic syndromes. Nature Genet 41: 838-842, 2009.

47. Mohamedali AM, Smith AE, Gaken J, Lea NC, Mian SA, Westwood NB, Strupp C, Gattermann N, Germing U and Mufti GJ: Novel TET2 mutations associated with UPD4q24 in myelodysplastic syndrome. J Clin Oncol 27: 4002-4006, 2009.

48. Kosmider O, Gelsi-Boyer V, Cheok M, et al: TET2 mutation is an independent favorable prognostic factor in myelodysplastic syndromes (MDSs). Blood 114: 3285-3291, 2009.

49. Tahiliani M, Koh KP, Shen Y, Pastor WA, Bandukwala $H$, Brudno Y, Agarwal S, Iyer LM, Liu DR, Aravind L and Rao A: Conversion of 5-methylcytosine to 5-hydroxymethylcytosine in mammalian DNA by MLL partner TET1. Science 324: 930-935, 2009.

50. Makishima H, Cazzolli H, Szpurka H, et al: Mutations of e3 ubiquitin ligase cbl family members constitute a novel common pathogenic lesion in myeloid malignancies. J Clin Oncol 27: 6109-6116, 2009

51. Gelsi-Boyer V, Trouplin V, Adelaide J, et al: Mutations of polycomb-associated gene ASXL1 in myelodysplastic syndromes and chronic myelomonocytic leukaemia. $\mathrm{Br} \mathrm{J}$ Haematol 145: 788-800, 2009

52. Boultwood J, Perry J, Pellagatti A, et al: Frequent mutation of the polycomb-associated gene ASXL1 in the myelodysplastic syndromes and in acute myeloid leukemia. Leukemia 24: 1062-1065, 2010.

53. Gondek LP, Tiu R, O'Keefe CL, Sekeres MA, Theil KS and Maciejewski JP: Chromosomal lesions and uniparental disomy detected by SNP arrays in MDS, MDS/MPD, and MDS-derived AML. Blood 111: 1534-1542, 2008.

54. Mohamedali A, Gäken J, Twine NA, et al: Prevalence and prognostic significance of allelic imbalance by single-nucleotide polymorphism analysis in low-risk myelodysplastic syndromes. Blood 110: 3365-3373, 2007.

55. Heinrichs S, Kulkarni RV, Bueso-Ramos CE et al: Accurate detection of uniparental disomy and microdeletions by SNP array analysis in myelodysplastic syndromes with normal cytogenetics. Leukemia 23: 1605-1613, 2009.

56. Andreakos E, Foxwell B and Feldmann M: Is targeting Toll-like receptors and their signaling pathway a useful therapeutic approach to modulating cytokine-driven inflammation? Immunol Rev 202: 250-265, 2004.

57. Takeda K, Kaisho T and Akira S: Toll-like receptors. Annu Rev Immunol 21: 335-276, 2003.

58. Rakoff-Nahoum S and Medzhitov R: Toll-like receptors and cancer. Nature Rev Cancer 9: 57-63, 2009.

59. Kuninaka N, Kurata M, Yamamoto K, Suzuki S, Umeda S, Kirimura S, Arai A, Nakagawa Y, Suzuki K and Kitagawa M: Expression of Toll-like receptor 9 in bone marrow cells of myelodysplastic syndromes is down-regulated during transformation to overt leukemia. Exp Mol Pathol 88: 293-298, 2010.

60. Buonamici S, Li D, Chi Y, Zhao R, Wang X, Brace L, Ni H, Saunthararajah Y and Nucifora G: EVIl induces myelodysplastic syndrome in mice. J Clin Invest 114: 713-719, 2004.

61. Grisendi S, Bernardi R, Rossi M, Cheng K, Khandker L, Manova K and Pandolfi PP: Role of nucleophosmin in embryonic development and tumorigenesis. Nature 437: 147-153, 2005

62. Lin YW, Slape C, Zhang Z and Aplan PD: NUP98-HOXD13 transgenic mice develop a highly penetrant, severe myelodysplastic syndrome that progresses to acute leukaemia. Blood 106: 287-295, 2005.

63. Watanabe-Okochi N, Kitaura J, Ono R, Harada H, Harada Y, Komeno Y, Nakajima H, Nosaka T, Inaba T and Kitamura T: AML1 mutations induced MDS and MDS/AML in a mouse BMT model. Blood 111: 4297-4308, 2008 